\title{
$\checkmark$ Research Square \\ Hydrologic regime alteration and influence factors in the Jialing River of the Yangtze River, China
}

\section{Wenxian Guo}

North China University of Water Conservancy and Electric Power

\section{Xuyang Jiao}

North China University of Water Conservancy and Electric Power

\section{Haotong Zhou}

North China University of Water Conservancy and Electric Power

Yongwei Zhu

North China University of Water Conservancy and Electric Power

Hongxiang Wang ( $\nabla$ wanghongxiang@ncwu.edu.cn )

North China University of Water Conservancy and Electric Power

\section{Research Article}

Keywords: Jialing River basin, hydrological regime, IHA-RVA method, hydrological alteration degree, ecological restoration

Posted Date: January 28th, 2022

DOI: https://doi.org/10.21203/rs.3.rs-1213729/v1

License: (c) (i) This work is licensed under a Creative Commons Attribution 4.0 International License.

Read Full License 
Hydrologic regime alteration and influence factors in the Jialing River of the Yangtze River, China

\author{
Wenxian Guo ${ }^{1}$, Xuyang Jiao ${ }^{1}$, Haotong Zhou ${ }^{1}$, Yongwei Zhu ${ }^{2}$, Hongxiang Wang,"* \\ (1. College of Water Resources, North China University of Water Resources and Electric Power, Zhengzhou \\ 450045, China. 2. School of Water Conservancy, North China University of Water Resources and Electric Power, \\ Zhengzhou 450045, China. Correspondence and requests for materials should be addressed to H.W. (email: \\ wanghongxiang@ncwu.edu.cn))
}

Abstract: Under the influence of climate alteration and human activities, the hydrological regime of rivers is changing dramatically, which has become a hot spot for water environment research. In this study, we quantitatively assessed the degree of hydrological variability of the Jialing River and the contribution of climate alteration and human activities to hydrological alterations using the ecohydrological indicator range of alteration (IHA-RVA) method and Budyko hypothesis formulations. The results showed that (1) The average annual runoff and the precipitation of Jialing River showed a decreasing trend, the potential evapotranspiration showed an increasing trend. (2) Compared with before the hydrological situation changed, the degree of alteration in the annual extreme streamflow is $31 \%$, which is a low degree of alteration; the degree of alteration in monthly streamflow, annual extreme flow magnitude, extreme flow ephemeris, and streamflow alteration frequency are $51 \%, 43 \%, 54 \%$, and $64 \%$ respectively, which are all moderate degrees of alteration; the overall hydrological alteration is $50 \%$, which belongs to moderate alteration. (3) The contribution of precipitation, potential evapotranspiration, and human activities to the runoff alteration is $61 \%,-16 \%$, and $55 \%$, respectively. This study provides corresponding references for ecological restoration and sustainable development of the Yangtze River Basin in China.

Keywords: Jialing River basin. hydrological regime. IHA-RVA method. hydrological alteration degree. ecological restoration.

\title{
Introduction
}

The river hydrology regime is a dynamic feature of its ecosystem that determines river materials and energy exchange. Alterations in the hydrological regime of rivers will directly affect the stability of ecosystems in the basin and the utilization and development of regional water resources $^{1}$. With the increasing climate variability and anthropogenic disturbances, the hydrological regime of important rivers around the world has d to some extent, such as Amazon ${ }^{2}$, Mississippi ${ }^{3}$, Nile $^{4}$, Yellow River ${ }^{5}$, and Yangtze ${ }^{6}$. In China, the large-scale construction of reservoirs in the Yangtze River basin since the 1960s, along with the soil and water conservation work in the Yangtze River basin, these large-scale human activities are bound to seriously disturb the alterations in the hydrological regime of the Yangtze River ${ }^{7}$. As one of the main tributaries of the upper reaches of the Yangtze River, the Jialing River has a significant runoff and precipitation, making it a tributary with a considerable potential for water resources exploitation on the Yangtze River ${ }^{8}$. Therefore, it is of great significance for the ecological restoration and sustainable development of the Yangtze River Basin to study the hydrological alterations of the Jialing River Basin and to evaluate the influence of various influencing factors on runoff qualitative and quantitatively.

Currently, Richter et al. have summarized 33 ecologically significant IHA (Indicators of Hydrologic Alteration) in terms of streamflow, frequency, duration, timing, and rate of alteration to 
summarize the overall characteristics of river hydrologic phenomenon ${ }^{9}$. On this basis, the Range of Variability Approach (RVA) was proposed to quantitatively evaluate the degree of hydrologic regime alteration of one or more elements under specific activities ${ }^{10-11}$. The results can better reflect the degree of hydrologic alteration. Wei et al. ${ }^{12}$ applied the RVA method to study the hydrological variability and river-lake relationship between Poyang Lake and the middle and lower reaches of the Yangtze River. Guo et al. ${ }^{13}$ assessed the analysis of the extent of hydrological alterations in the lower Three Gorges and the impact of hydrological alterations on spawning ground habitat conditions of important fish by the RVA method. Zuo et al. ${ }^{14}$ quantified the effect of dams and sluice gates on the river potential of the Sha Ying River using the RVA method as an example. Mwanza et $a l .{ }^{15}$ similarly used this method to analyze the extent of alteration of hydrological indicators at different sections of the Manyame basin in Zimbabwe after the construction of dams. Meanwhile, for the attribution analysis of runoff alterations, scholars in recent years have mainly adopted various hydrological models, cumulative slope rate of alteration, elasticity coefficient method, and other methods to analyze the influencing factors of runoff alterations in different rivers. The elasticity coefficient method based on Budyko's theory incorporates evapotranspiration into climate influencing factors. In contrast, this method has the advantages of easy application and high feasibility, and this method is widely used in essential river basins around the world ${ }^{16-19}$. In summary, studies on the quantitative evaluation of alterations in river hydrological conditions are dominated by IHA, RVA, and the elasticity coefficient method. Their results can better reflect the degree of alteration in rivers after being influenced.

Some scholars have conducted studies on the alterations in the hydrological regime of the Jialing River from different perspectives. Li et al. ${ }^{20}$ analyzed the trend and mutation of Jialing River runoff and sediment based on the hydrological data of long time series in the last 60 years and summarized the role of reservoir construction and ecological engineering on runoff alterations. Liu et al. ${ }^{21}$ based on the longitudinal profile of the main terrace reservoirs of the Jialing River, used GIS methods and digital elevation model data to quantitatively analyze the alterations in the water area, runoff, and sediment after dam impoundment and concluded that the completion of the terrace reservoirs has a significant impact on the hydrological situation of the river and almost determines the trend of the hydrological status of the mainstream section. Zhou et al. ${ }^{22}$ used the double cumulative curve method to quantitatively evaluate the effects of dams, vegetation cover, and precipitation on runoff variability. In summary, most researchers ${ }^{20-21}$ have limited the identification of runoff variability only to its trend and mutation points. However, there is a lack of in-depth research on the variability of each hydrological index of runoff and the degree. Meanwhile, for the attribution analysis of runoff alterations in the Jialing River, some scholars ${ }^{22}$, although quantitatively evaluating the contribution of different factors, lacked to consider the influence of river evapotranspiration and the response between runoff alterations and each element. At the same time, there is a lack of qualitative analysis of the effects of alterations in hydrological regimes on the aquatic organisms in the Jialing River basin due to the lack of information on marine organisms in the bay, so further research is needed for such issues.

In view of the deficiency of the current research on the hydrological regime alteration of Jialing River, this study is based on the daily hydrological data of Beibei Hydrological Station, a representative hydrological station of Jialing River, from 1956 to 2020. Its main research purposes are: (1) To analyze the long-term series alteration characteristics of hydrological and meteorological elements in the Jialing River basin; (2) Analyze the alteration of the hydrological situation in five 
aspects of monthly flow, frequency, duration, timing, and variable rate of Jialing River before and after mutation, and comprehensively evaluate the alteration degree of the overall hydrological situation; (3) Quantitatively evaluate the contribution rate of climate alteration and human activities to the alteration of hydrological situation. To provide a scientific basis for the restoration of water environment and water ecology and water resources development and utilization in the upper Yangtze River basin.

\section{Results}

\section{Trend analysis of hydro-meteorological factors}

Figure 1 shows the interannual trends of streamflow (S), runoff depth (R), precipitation (P), and potential evapotranspiration (ET $)$ in the Jialing River basin from 1956 to 2020. According to Figure 1(a) and Figure 1(b), The annual average streamflow and runoff depth of Jialing River

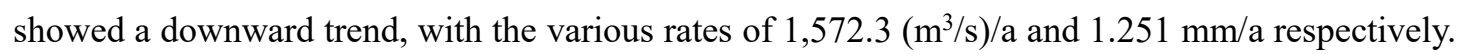
As shown in Figure 1(c), The annual precipitation in the Jialing River basin shows a decreasing trend with a variable rate of $0.899 \mathrm{~mm} / \mathrm{a}$. According to the 5 a sliding average process line, the runoff volume and precipitation volume maintain good consistency, with an overall performance of first decreasing, then increasing; then This indicates that precipitation and runoff are positively correlated and have a high degree of synchronization. According to Fig. 1(d), the potential evapotranspiration in the basin shows a rising trend with a rate of alteration of $1.3462 \mathrm{~mm} / \mathrm{a}$. The potential evapotranspiration shows a decreasing trend until 1985, and the decreasing trend is more significant than that of precipitation and runoff. Then it shows a rising trend and decreases again in 2010, opposite to the direction of rainfall and runoff.
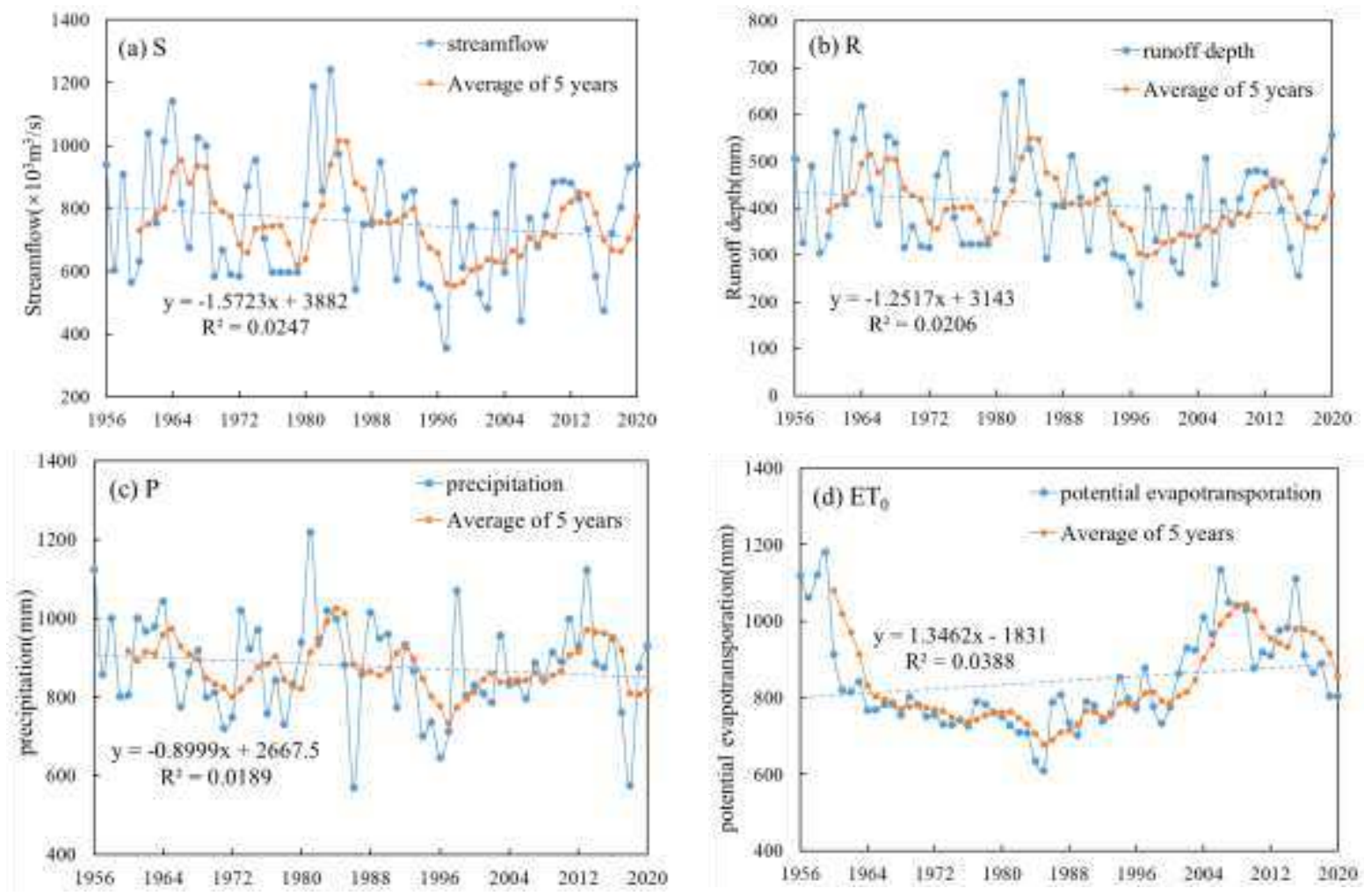

Fig. 1 Interannual alteration of (a)streamflow, (b)runoff depth, (c)precipitation and (d)potential evapotranspiration. 


\section{Analysis of runoff mutation}

The Mann-Kendall mutation test principle was used to calculate and plot its mutation test curve, while the cumulative distance level method was used for reference, and the results are shown in Fig. 2. According to Fig. 2(a), the UF and UB curves intersected several times within the $90 \%$ confidence interval, corresponding to $1975,1982,1985$, and 1993, respectively. The cumulative distance level method was used to synthesize the results to further confirm the mutation years. According to Fig. 2(b), the annual mean streamflow showed a significant alteration in the 1980s and turned in 1980, 1985, and 1993, consistent with the M-K test results. The year 1985 was adopted as a mutation in a runoff for careful consideration. The streamflow, runoff depth, precipitation, and potential evaporation alterations were analyzed according to the mutation point. The results are shown in Table 1.
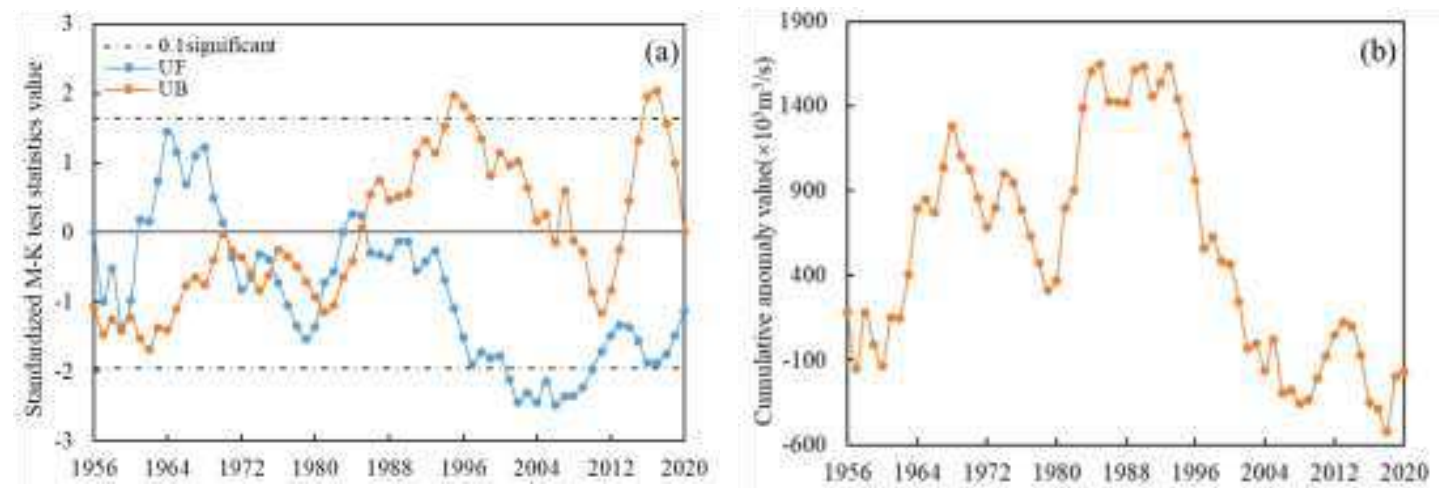

Fig. 2 (a) M-K mutation test. (b)Cumulative anomaly test.

Tab.1 Mutability analysis of streamflow, runoff depth, precipitation, and potential evaporation

\begin{tabular}{ccccc}
\hline Period & $\mathrm{S}\left(\times 10^{3} \mathrm{~m}^{3} / \mathrm{s}\right)$ & $\mathrm{R}(\mathrm{mm})$ & $\mathrm{P}(\mathrm{mm})$ & $\mathrm{ET}_{0}(\mathrm{~mm})$ \\
\hline The whole period & 756.21 & 409.22 & 871.54 & 845.66 \\
Base Period & 810.83 & 431.14 & 893.71 & 799.59 \\
Period of alteration & 709.39 & 367.12 & 842.49 & 914.44 \\
Amount of alteration & -101.43 & -64.01 & -51.22 & 114.84 \\
\hline
\end{tabular}

\section{Hydrological regime alteration analysis}

Comprehensive 4.2 part of the mutation test results analysis results, respectively, the daily runoff period before $1985(1956 \sim 1985)$ as the natural runoff series, after $1985(1986 \sim 2020)$ as the runoff alteration series, based on this application of IHA and RVA method to calculate the degree of runoff alteration before and after the mutation Beibei hydrological station, the calculation results are shown in Table 2.

Tab.2 IHA index statistics table before and after a mutation in Jialing River

\begin{tabular}{clcccc}
\hline \multirow{2}{*}{ IHA Indicators } & \multicolumn{2}{c}{ Median value } & \multicolumn{2}{c}{ Hydrological alteration degree } \\
\cline { 3 - 6 } & January $\left(\mathrm{m}^{3} \cdot \mathrm{s}^{-1}\right)$ & Pre-impact & Post-impact & value \% & Degree \\
\hline & February $\left(\mathrm{m}^{3} \cdot \mathrm{s}^{-1}\right)$ & 433.5 & 536.5 & 77.38 & $\mathrm{H}$ \\
\cline { 2 - 6 } Group 1 & 363.8 & 415.3 & 32.14 & $\mathrm{~L}$ \\
& March $\left(\mathrm{m}^{3} \cdot \mathrm{s}^{-1}\right)$ & 391 & 532 & 66.07 & $\mathrm{H}$ \\
& April $\left(\mathrm{m}^{3} \cdot \mathrm{s}^{-1}\right)$ & 838.8 & 823 & 17.86 & $\mathrm{~L}$ \\
& May $\left(\mathrm{m}^{3} \cdot \mathrm{s}^{-1}\right)$ & 1668 & 1695 & 20.83 & $\mathrm{~L}$ \\
& $\operatorname{June}\left(\mathrm{m}^{3} \cdot \mathrm{s}^{-1}\right)$ & 1565 & 1375 & 15.56 & $\mathrm{~L}$ \\
& $\operatorname{July}\left(\mathrm{m}^{3} \cdot \mathrm{s}^{-1}\right)$ & 3650 & 2605 & 77.38 & $\mathrm{H}$
\end{tabular}




\begin{tabular}{|c|c|c|c|c|c|}
\hline & August $\left(\mathrm{m}^{3} \cdot \mathrm{s}^{-1}\right)$ & 2975 & 2270 & 69.64 & $\mathrm{H}$ \\
\hline & September $\left(\mathrm{m}^{3} \cdot \mathrm{s}^{-1}\right)$ & 2733 & 2435 & 69.64 & $\mathrm{H}$ \\
\hline & $\operatorname{October}\left(\mathrm{m}^{3} \cdot \mathrm{s}^{-1}\right)$ & 1990 & 1745 & 43.45 & M \\
\hline & November $\left(\mathrm{m}^{3} \cdot \mathrm{s}^{-1}\right)$ & 1085 & 1128 & 20.83 & $\mathrm{~L}$ \\
\hline & December $\left(\mathrm{m}^{3} \cdot \mathrm{s}^{-1}\right)$ & 557 & 596 & 20.83 & $\mathrm{~L}$ \\
\hline \multirow{11}{*}{ Group 2} & 1-day minimum $\left(\mathrm{m}^{3} \cdot \mathrm{s}^{-1}\right)$ & 328.5 & 274 & 66.07 & $\mathrm{H}$ \\
\hline & 3-day minimum $\left(\mathrm{m}^{3} \cdot \mathrm{s}^{-1}\right)$ & 333.3 & 296.7 & 1.786 & $\mathrm{~L}$ \\
\hline & 7-day minimum $\left(\mathrm{m}^{3} \cdot \mathrm{s}^{-1}\right)$ & 336.3 & 329.1 & 20.83 & $\mathrm{~L}$ \\
\hline & 30-day $\operatorname{minimum}\left(\mathrm{m}^{3} \cdot \mathrm{s}^{-1}\right)$ & 349.2 & 402.6 & 57.78 & M \\
\hline & 90-day minimum $\left(\mathrm{m}^{3} \cdot \mathrm{s}^{-1}\right)$ & 422.1 & 515.6 & 32.14 & $\mathrm{~L}$ \\
\hline & 1-day maximum $\left(\mathrm{m}^{3} \cdot \mathrm{s}^{-1}\right)$ & 22200 & 19950 & 43.45 & M \\
\hline & 3-day maximum $\left(\mathrm{m}^{3} \cdot \mathrm{s}^{-1}\right)$ & 18680 & 16340 & 20.83 & $\mathrm{~L}$ \\
\hline & 7-day maximum $\left(\mathrm{m}^{3} \cdot \mathrm{s}^{-1}\right)$ & 14660 & 12090 & 54.76 & M \\
\hline & 30-day maximum $\left(\mathrm{m}^{3} \cdot \mathrm{s}^{-1}\right)$ & 7605 & 5930 & 26.11 & $\mathrm{~L}$ \\
\hline & 90-day maximum $\left(\mathrm{m}^{3} \cdot \mathrm{s}^{-1}\right)$ & 5178 & 3815 & 43.45 & M \\
\hline & Base flow index $\left(\mathrm{m}^{3} \cdot \mathrm{s}^{-1}\right)$ & 0.1541 & 0.1951 & 43.45 & M \\
\hline \multirow{2}{*}{ Group 3} & Date of minimum(ds) & 60 & 50 & 31.14 & $\mathrm{~L}$ \\
\hline & Date of maximum(ds) & 200 & 210 & 30.67 & $\mathrm{~L}$ \\
\hline \multirow{4}{*}{ Group 4} & Low pulse count(times) & 2 & 13 & 82.41 & $\mathrm{H}$ \\
\hline & Low pulse duration(ds) & 37.75 & 2 & 63.46 & M \\
\hline & High pulse count(times) & 9 & 9 & 24.6 & $\mathrm{~L}$ \\
\hline & High pulse duration(ds) & 6 & 5 & 16.18 & $\mathrm{~L}$ \\
\hline \multirow{3}{*}{ Group 5} & Rise rate $\left(\mathrm{m}^{3} \cdot \mathrm{d}^{-1}\right)$ & 114.5 & 108.5 & 32.14 & $\mathrm{~L}$ \\
\hline & Fall rate $\left(\mathrm{m}^{3} \cdot \mathrm{d}^{-1}\right)$ & -70 & -127 & 36.67 & M \\
\hline & Number of reversals(times) & 102.5 & 159.5 & 100 & $\mathrm{H}$ \\
\hline
\end{tabular}

Note: $\mathrm{H}$ indicates a high degree of alteration, $\mathrm{M}$ indicates moderate alteration, $\mathrm{L}$ indicates a low degree of alteration.

(1) Monthly median streamflow magnitude. Figure 3 shows the comparison of the monthly median streamflow before and after the alteration of the hydrological situation of the Jialing River.

130 According to the comparison chart, it can be concluded that the changed Beibei station has different 131 degrees of increase in streamflow from November to April and June of the coming year, among 132 which the growth is more evident in January and March, and the degree of alteration reaches a high 133 degree of alteration; while the monthly median streamflow from July to October and April has 134 different degrees of decrease, and the degree of decline is more evident than the degree of increase.

135 A high degree of alteration is reached in July, August, and September. 

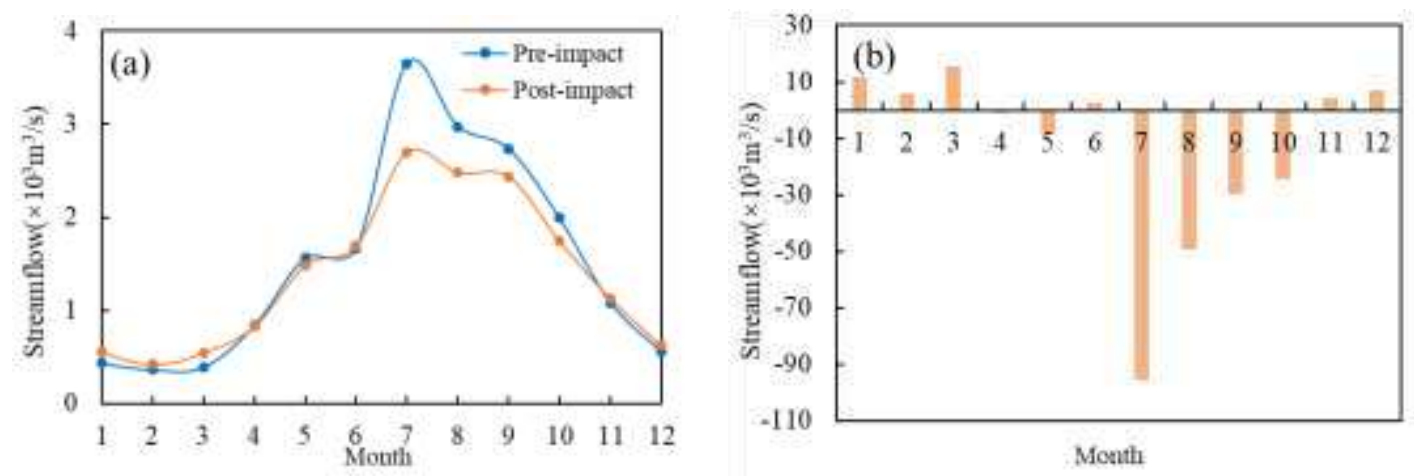

Fig.3 (a) Alteration of the monthly streamflow before and after. (b) Monthly streamflow difference before and after changing.

(2) The magnitude of the extreme annual streamflow. Figure 4 shows the extreme yearly streamflow alteration. As can be seen from the figure: the minimum 1, 3, and $7 \mathrm{~d}$ streamflow have decreased to different degrees, while the minimum $30 \mathrm{~d}$ and $90 \mathrm{~d}$ streamflow show an increase, in which the annual average minimum $1 \mathrm{~d}$ streamflow has an apparent decreasing trend, and the degree of alteration reaches $66 \%$, which is close to a high degree of alteration; the annual extreme values after the impact are all lower than those before the effect. This is consistent with the results of the $\mathrm{M}-\mathrm{K}$ trend test that the runoff depth of Jialing River shows a decreasing trend.

(3) The time of occurrence of extreme annual streamflow. The yearly minimum and maximum streamflow occurrence times at Beibei hydrological station are changed by less than $33 \%$, which are mildly changed. Among them, the time of the maximum runoff is delayed by $11 \mathrm{~d}$, which indicates that the construction of the Jialing River Reservoir has made the high streamflow time within a stable range.

(4) Frequency and duration of high and low streamflow. The number of high pulses and the calendar time of Beibei station both have different degrees of decrease, among which the number of high pulses decreased from 9 to 8 , the degree of alteration was $24 \%$. The calendar time of high pulses fell from $6 \mathrm{~d}$ to $5 \mathrm{~d}$, the degree of alteration is $16 \%$, both of which are less than $33 \%$, which is a mild alteration; while the number of low pulses increased from 2 to 13 , the degree of alteration is $82 \%$, which is a high chance, and the calendar time of intense pulses decreased from $37 \mathrm{~d}$ to $2 \mathrm{~d}$, with $63 \%$ alteration.

(5) The streamflow rate of alteration and frequency. Beibei hydrological station runoff rate of rising hydrological alteration degree and fall rate hydrological alteration degree is $32 \%$ and $36 \%$, respectively, both close to moderate alteration. The number of reversals has increased significantly compared with before the impact, and the degree of alteration has reached $100 \%$. Since the ecosystem has limited ability to recover from external influences, the frequency alteration of Jialing River runoff will significantly impact the ecosystem in its basin ${ }^{23}$. 

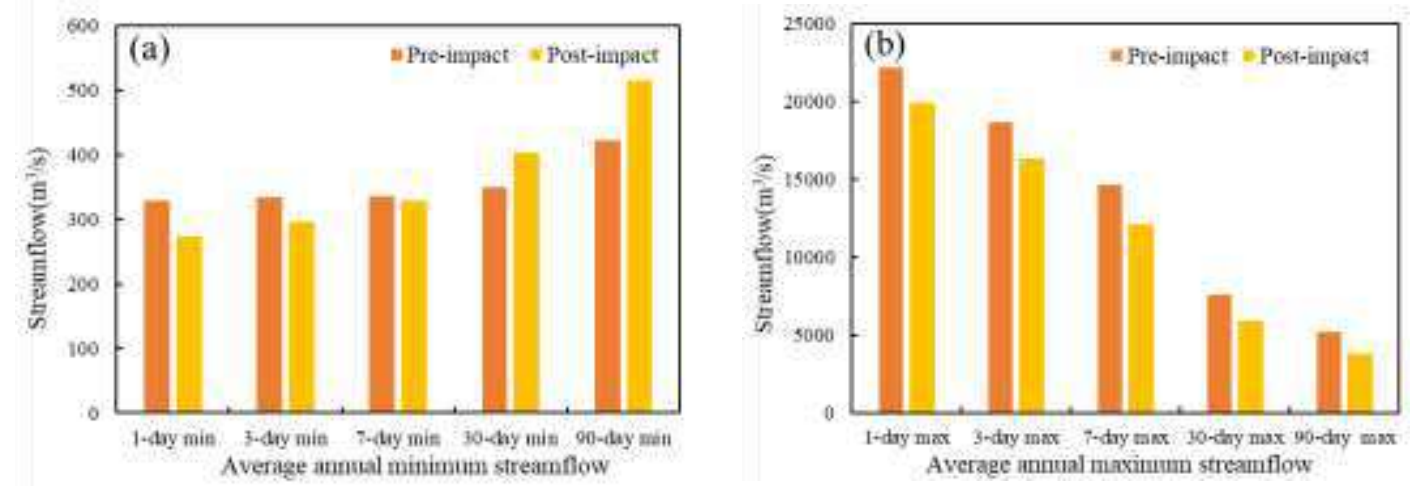

Fig.4 (a)Minimum streamflow alteration. (b)Maximum streamflow alteration.

Based on the IHA-RVA method, 32 hydrological indicators of the Beibei hydrological station before and after the hydrological regime were analyzed in absolute terms. The results are shown in Figure 5. The hydrological indicators of moderate alteration reach 10 , accounting for $32 \%$ of the total hydrological indicators, among which the median streamflow in March and the annual average minimum $1 \mathrm{~d}$ streamflow hydrological alteration degree reaches $66 \%$, close to the significant alteration; the hydrological indicators of low alteration reach 16 , accounting for $50 \%$ of the total hydrological indicators. The formula calculates the overall hydrological index alteration degree and the hydrological index alteration degree of each group. The specific results are shown in Table 3. according to the results of the table can be concluded: Beibei hydrological station except for the third group of indicators for low alteration degree, the rest belong to medium alteration degree; the fifth group alteration degree is $64 \%$, close to significant alteration; the overall hydrological index alteration degree is $50 \%$, belong to medium alteration.

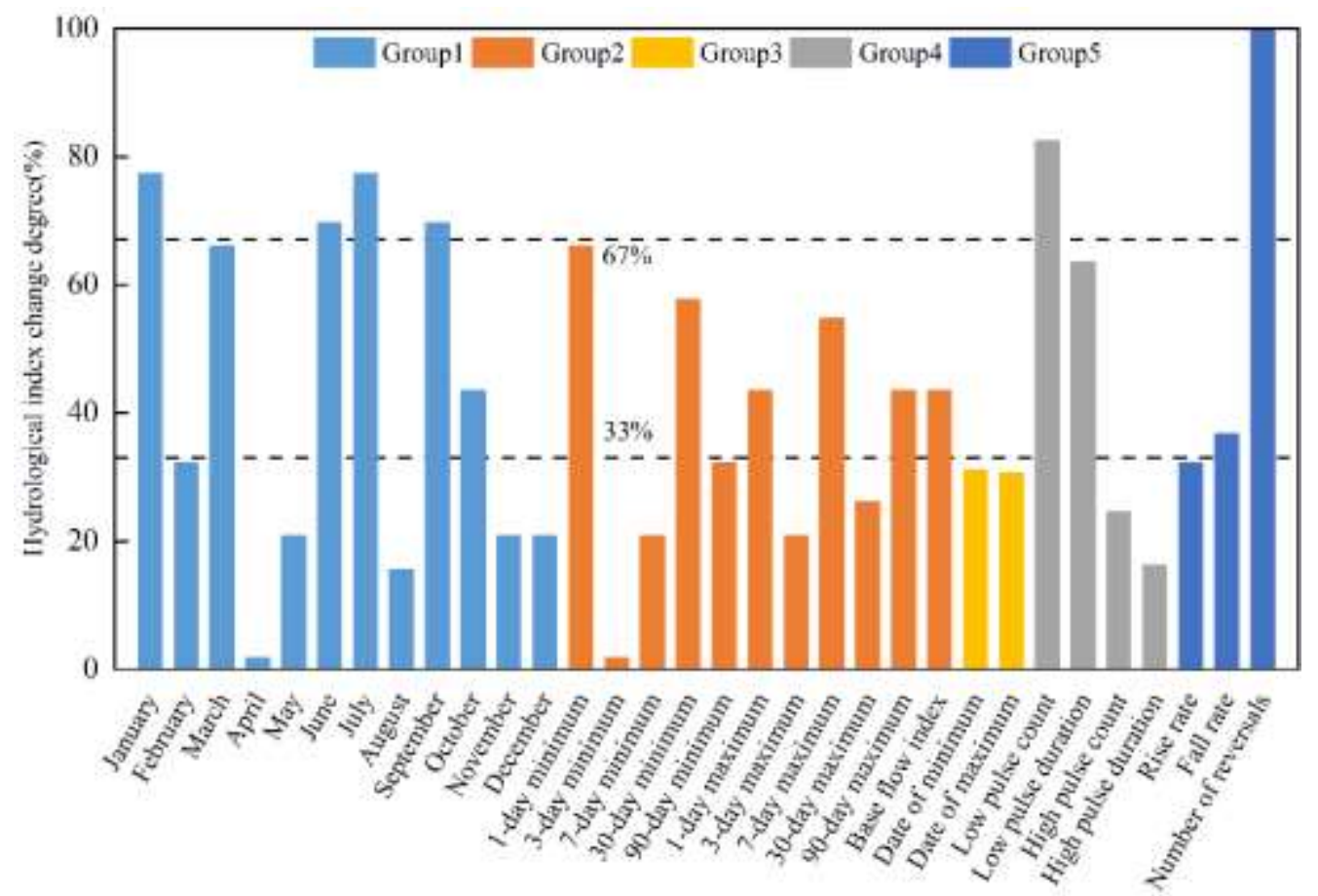

Fig.5 Hydrological alteration degree of Beibei station Tab.3 Overall hydrological alteration of discharge sequence Unit (\%)

\begin{tabular}{ccccccc}
\hline $\begin{array}{c}\text { Hydrological } \\
\text { stations }\end{array}$ & Group 1 & Group 2 & Group 3 & Group 4 & Group 5 & $\begin{array}{c}\text { Overall } \\
\text { hydrological } \\
\text { alteration degree }\end{array}$ \\
\cline { 2 - 6 } Beibei & $51(\mathrm{M})$ & $43(\mathrm{M})$ & $31(\mathrm{~L})$ & $54(\mathrm{M})$ & $64(\mathrm{M})$ & $50(\mathrm{M})$ \\
\hline
\end{tabular}




\section{Attribution analysis of runoff alterations}

The formulae based on the six Budyko assumptions calculate the contribution of different influencing factors, and the calculation results are shown in Table 4. According to the data in the table, the ranges of runoff depth alteration caused by rainfall, potential evapotranspiration, and human activities are $-32.96 \sim-45.29 \mathrm{~mm}, 7.28 \sim 13.62 \mathrm{~mm}$, and $-32.34 \sim-38.28 \mathrm{~mm}$, respectively, and the mean values are $-39.017 \mathrm{~m}, 10.288 \mathrm{~mm},-35.408 \mathrm{~mm}$, so the mean value of runoff depth alteration calculated based on the six Budyko hypothesis formulas is $-64.13 \mathrm{~mm}$. While the actual runoff depth alteration in the study area is $-64.01 \mathrm{~mm}$, and the error range between them is $0.11 \mathrm{~mm}$, indicating that the Budyko hypothesis-based hydrothermal coupling equilibrium principle of the elasticity coefficient method applies the runoff alteration attribution analysis in this study area. The contribution of precipitation to runoff alteration ranged from $51 \%$ to $71 \%$, with a mean value of $61 \%$; the gift of potential evapotranspiration to runoff alteration ranged from $-11 \%$ to $-21 \%$, with a mean value of $-16 \%$; and the contribution of human activities to runoff alteration ranged from $51 \%$ to $70 \%$, with a mean value of $55 \%$.

Tab.4 Attribution Analysis of Hydrological regime

\begin{tabular}{cccccccc}
\hline Indicators & Zhang & $\mathrm{Fu}$ & Schreiber & Budyko & Pike & Ol'dekop & $\begin{array}{c}\text { Average } \\
\text { value }\end{array}$ \\
\hline$\Delta R_{P} / m m$ & -37.30 & -38.91 & -38.03 & -32.96 & -41.59 & -45.29 & -39.01 \\
$\Delta R_{E} / m m$ & 9.35 & 10.17 & 9.73 & 7.28 & 11.55 & 13.62 & 10.28 \\
$\Delta R_{H} / m m$ & -36.10 & -35.58 & -35.86 & -38.28 & -34.26 & -32.34 & -35.40 \\
$\eta_{P} / \%$ & 58 & 60 & 59 & 51 & 65 & 71 & 61 \\
$\eta_{E} / \%$ & -14 & -15 & -15 & -11 & -18 & -21 & -16 \\
$\eta_{H} / \%$ & 56 & 55 & 56 & 70 & 54 & 51 & 55 \\
\hline
\end{tabular}

\section{Discussion}

\section{Impact of climate alteration on runoff}

Precipitation is the primary source of runoff, and its alteration directly impacts runoff ${ }^{24}$. Figure 7 shows the correlation analysis of runoff depth with precipitation and potential evapotranspiration before and after the impact, respectively, and according to the information in the figure, it can be seen that runoff depth and precipitation maintain the same trend, i.e., runoff depth increases with precipitation; from Figure 6(a), it can be seen that the growth rate of precipitation with runoff depth before and after the impact decreases from 0.944 to 0.621 from the base period to the alteration period, i.e., for every $100 \mathrm{~mm}$ increase in runoff depth, The correlation coefficient between runoff depth and precipitation decreases from 0.627 to 0.241 , which means that the influence of precipitation on runoff alterations in Jialing River gradually decreases.

Figure 6(b) shows that the changing trend of potential evapotranspiration and runoff depth in the Jialing River basin from 1956 to 2020 is opposite, i.e., the runoff depth decreases with the increase of potential evapotranspiration; the growth rate of potential evapotranspiration with runoff depth increases from 0.119 to 0.219 before and after the impact from the base period to the alteration period, i.e., the increase of precipitation alterations from $11.9 \mathrm{~mm}$ to $21.9 \mathrm{~mm}$ for every $100 \mathrm{~mm}$ increase of runoff depth The correlation coefficient between runoff depth and potential evapotranspiration increased from 0.0113 to 0.219 , however, even though the correlation coefficient increased, the correlation coefficient between potential evapotranspiration and runoff depth was more different than that between precipitation and runoff depth, which means that the alteration of Jialing River runoff was more influenced by rainfall. 
In summary, precipitation in the climate variability of the Jialing River basin is the main influencing factor leading to runoff alterations, which is consistent with the results of Guo et al. ${ }^{6}$, who predicted that runoff alterations in the Yangtze River basin are mainly influenced by precipitation and that alterations in potential evapotranspiration play a relatively minor role in determining runoff alterations. However, with the persistence of external influences, the influence of climate alteration on runoff is gradually weakening, while human activities are slowly dominating runoff alterations ${ }^{25}$.
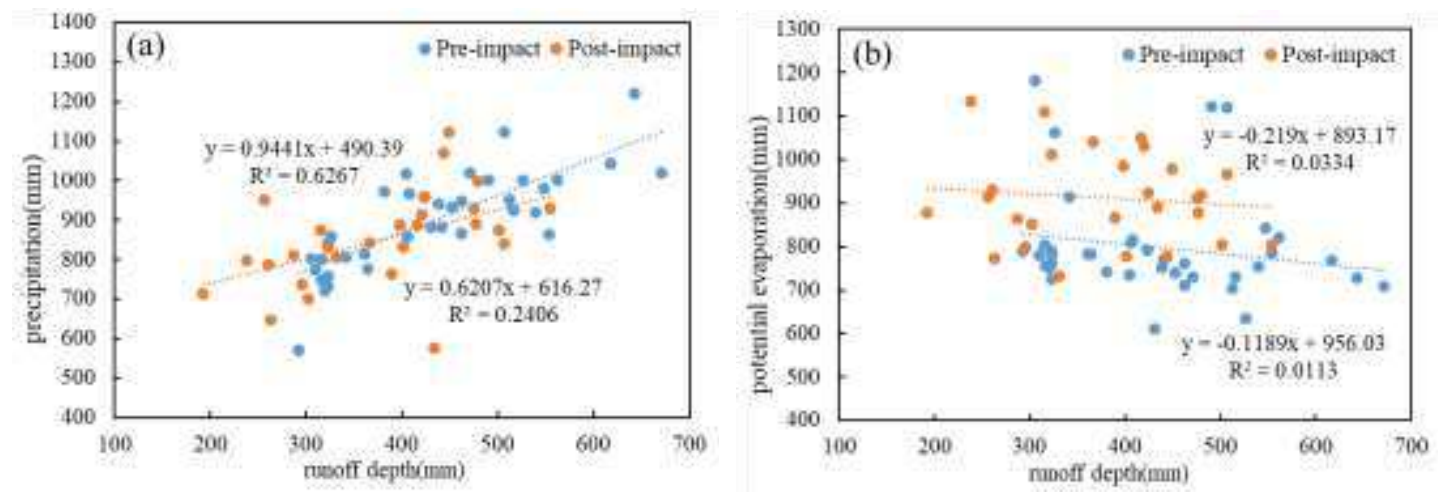

Fig.6 (a) Relationship between runoff depth and precipitation. (b) Relationship between Runoff Depth and Potential Evapotranspiration

\section{Impact of human activities on runoff}

The impact of human activities on runoff is mainly divided into two aspects: the construction of the reservoir and the alteration of underlying surface in the basin, where the water storage effect of the reservoir is mainly to regulate the intra-annual alteration of runoff, and the inter-basin water transfer projects reduce the annual runoff to some extent, but the amount of water transferred is less than $1 \%{ }^{26}$, so the alteration of the underlying surface is the human activity influence factor that mainly produces the reduction of runoff. Studies have shown that the underlying surface of a basin is primarily related to topography, soil composition, land use change, and vegetation cover. At long time scales, soil and topography are stable in the basin, and underlying surface alterations are mainly related to land use change and vegetation cover alterations.

Figure 7 and Table 5 show the distribution of land use in the Jialing River basin in different periods from 1980 to 2018. According to the information in the table, it can be seen that: grassland, cropland, and barren land in the basin have all decreased to different degrees, while forest, settlement, and wetland have all increased to different degrees; the conversion of cropland into the forest is the most prominent in the process of land use change, and its alteration area accounts for $7 \%$ of the whole basin area. 

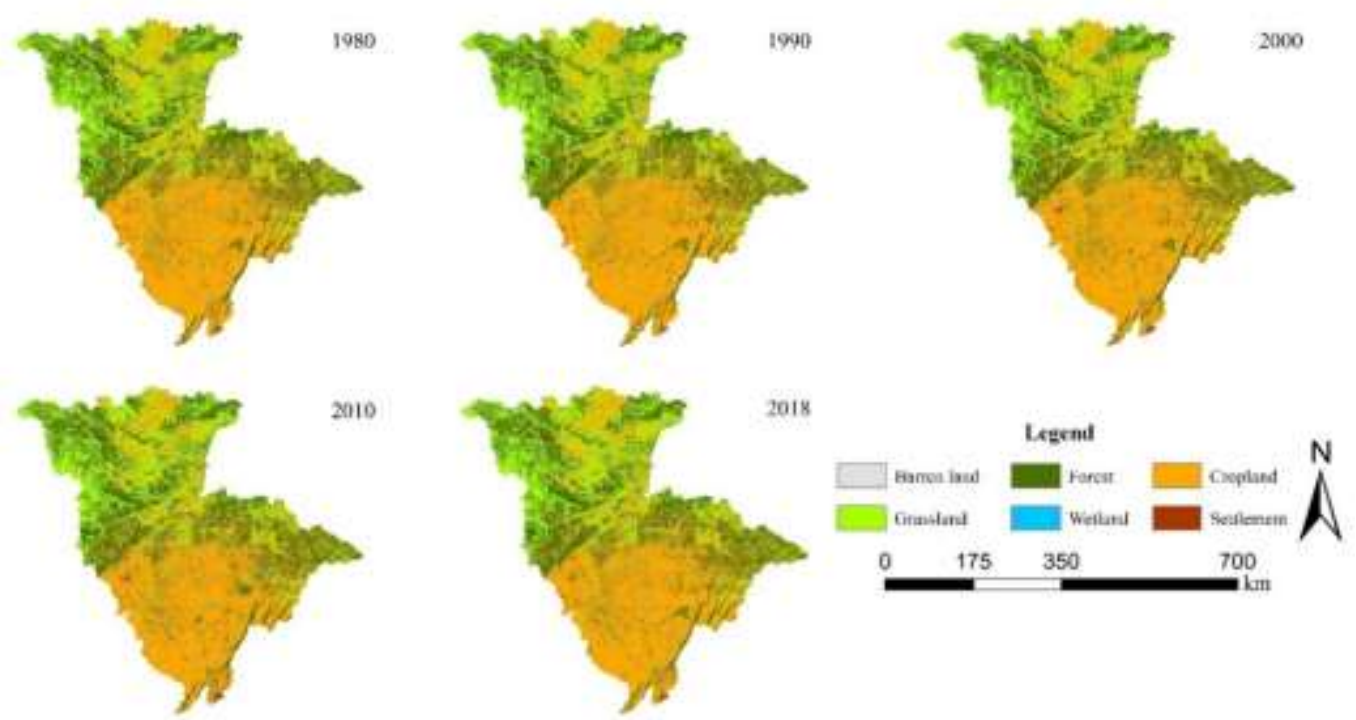

Fig. 7 Land use change map of Jialing River Basin from 1980 to 2018

Tab.5 Land use conversion matrix of Jialing River from 1980 to 2018 (unit: $\mathrm{km}^{2}$ )

\begin{tabular}{cccccccc}
\hline 198012018 & Grassland & Settlement & Cropland & Forest & Wetland & Barren land & Total \\
\hline Grassland & 18850.57 & 231.24 & 7635.86 & 8491.26 & 138.83 & 179.65 & 35527.43 \\
Settlement & 141.66 & 199.40 & 396.87 & 85.60 & 29.93 & - & 853.48 \\
Cropland & 7283.87 & 1877.84 & 50301.90 & 11292.89 & 1020.73 & 23.58 & 71800.84 \\
Forest & 7850.85 & 207.68 & 10747.06 & 31115.11 & 174.40 & 101.44 & 50196.56 \\
Wetland & 115.54 & 106.49 & 748.26 & 141.63 & 292.08 & 2.94 & 1406.96 \\
Barren land & 215.77 & 3.02 & 59.11 & 170.59 & 6.03 & 174.76 & 629.30 \\
Total & 34458.29 & 2625.68 & 69889.09 & 51297.09 & 1662.02 & 482.39 & 160414.59 \\
\hline
\end{tabular}

To reveal the cover of the Jialing River basin, the normalized vegetation index (NDVI) was used to describe the vegetation cover alteration process. Figure 8 show the results of spatial and temporal alterations of NDVI in the Jialing River basin, from which it can be seen that: the alterations of vegetation cover in the basin are mainly concentrated in the northern area of Jialing River, while the southern site does not show large fluctuations due to the gentle topography and urban concentration. According to the changing trend of NDVI value from 1998 to 2020, it can be seen that the NDVI value in Jialing River Basin is on the rise, that is, the vegetation coverage has gradually increased since the 1990s.

As mentioned above, there is a significant increase in forest land and vegetation cover in the Jialing River basin, attributed to the implementation of soil and water conservation in the Yangtze River basin. Since the performance of soil and water conservation work in 1989, the most severe areas of soil erosion in the basin have been reduced by $40 \%$ to $60 \%$, arable land has been reduced by nearly $80 \%$, and barren hills and slopes have disappeared ${ }^{27}$; as of 2008 , more than 5000 small basins have been treated in the upper reaches of the Yangtze River cumulatively, and $9.58 \times 10^{4} \mathrm{hm}^{2}$ of soil erosion treatment has been completed ${ }^{28}$. Soil erosion control has a pronounced effect on water reduction and storage of the land in the Jialing River basin, which has led to a decreasing trend of Jialing River runoff. 

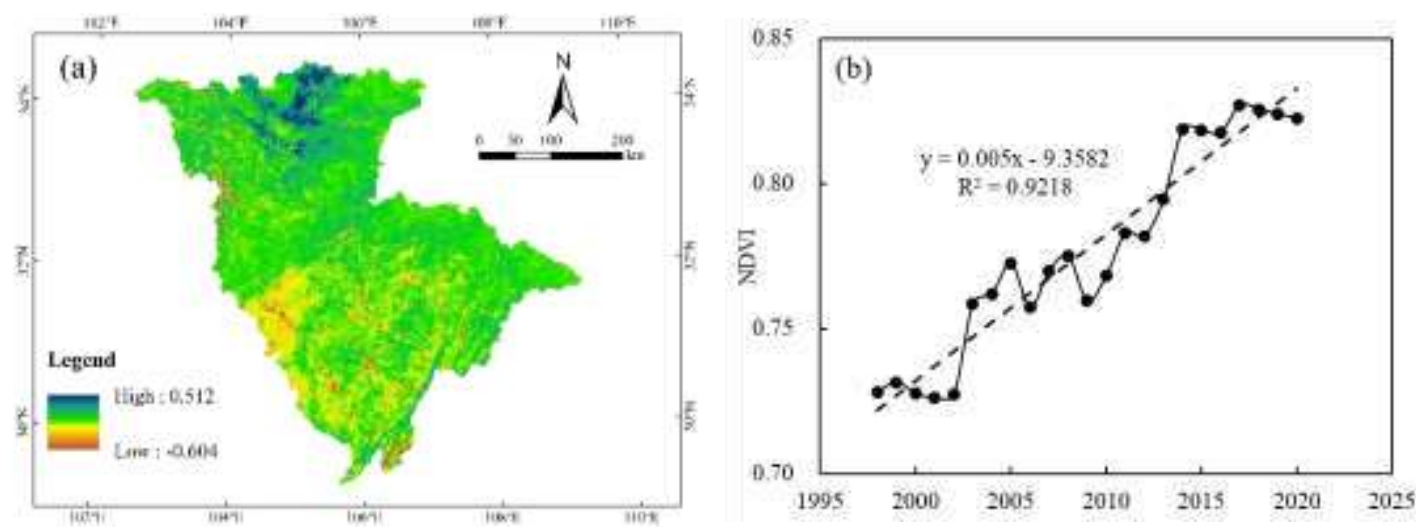

Fig. 8 (a) Temporal and Spatial Distribution of Vegetation Coverage in Jialing River Basin. (b) Interannual alteration of NDVI in Jialing River Basin.

\section{Effects of Runoff Change on Fishes}

Fish resources are an important part of aquatic living resources, and the stability of its population is affected by reservoir construction ${ }^{29}$. Since the1980s, the Jialing River Basin began to build a variety of large dams, especially after1990 (Table6). At present, the Jialing River basin is rich in fish diversity. There are many endemic fish species in the basin, ranking 4 th among all water systems in the Yangtze River basin ${ }^{30}$. Compared to the 1980 survey on the status and alterations of fishery resources in the middle and lower reaches of the Jialing River, the study results in 2010 showed that three main fish species decreased in the Jialing River basin. The first is the spawning of drifting fish. The spawning of these fish requires a certain amount of water stimulation. After the hydrological situation in the Jialing River Basin alterations, the high flow of rivers decreases, which inhibits the reproduction of these fish. In addition, due to the dam barrier, its living space is hindered, such as Ctenopharyngodon Idella, Sinibotia superciliaris and Leptobotia elongata, etc. The second is some fish adapted to the rapid flow habitat. Due to the shortening of the high pulse duration of the river and the delay of the occurrence time of the maximum flow, the runoff alterations slowly and tends to be reservoirized, so that it cannot meet the specific habitat, such as Onychostoma sima, Cornelius guichenoti, etc. Thirdly, Cyprinidae fish, the main economic source of fishery in Jialing River, has decreased in species and quantity, among which the species has dropped from 58 to 46 , and the proportion of the number has dropped from $84 \%$ to $66 \%$. The reason is that the reservoirization of rivers makes some fishing operations easy to carry out, which greatly increases the arrest rate ${ }^{31}$.

With the completion of various types of reservoirs in the upper reaches of the Yangtze River, the connection between the mainstem and major tributaries of the Yangtze River is blocked, and the passage of fish migration in the river is hindered ${ }^{32}$. Therefore, for fish conservation under the completion with the trapezoidal reservoirs should pay attention to the degree of their hydropower development, dismantle some reservoirs that have a slight impact range. Natural streamflow patterns and hydrological rhythms can be restored to provide a suitable habitat for some migratory and other endangered fishes unique to the upper reaches of the Yangtze River ${ }^{33}$.

Tab.6 Construction of main reservoirs in Jialing River Basin

\begin{tabular}{ccccc}
\hline Reservoir & Position & $\begin{array}{c}\text { Controlled drainage area } \\
\left(\mathrm{km}^{2}\right)\end{array}$ & Operation time & Storage capacity $\left(\mathrm{km}^{3}\right)$ \\
\hline Shengzhong & Xi river & 1,756 & 1984 & 1.34 \\
Baozhushi & Bailong river & 28,428 & 1996 & 2.55 \\
Caojie & Jialing river & 156,100 & 2011 & 2.22 \\
Tingzikou & Jialing river & 62,550 & 2013 & 4.12 \\
\hline
\end{tabular}




\section{Conclusions}

(1) During the period 1956-2020, the runoff in the Jialing River basin showed an overall decreasing trend, the precipitation showed an overall decreasing trend, the potential evapotranspiration showed an overall increasing trend, and the mutation in runoff occurred in 1985.

(2) Compared with before the mutation, the monthly median flow after the mutation decreased in July-November and May, and increased in December-April and June; the annual maximum flow showed a decreasing trend after the mutation, the annual minimum 30 and $90 \mathrm{~d}$ flow increased, and the annual minimum 1, 3 and $7 \mathrm{~d}$ flow decreased; the extreme flow ephemeris showed a decreasing trend, the number of high flows decreased and the occurrence time was delayed, the number of low flows increased and The alteration range is about 10d; the rising rate, fall rate and reversal all increase; in general, the alteration degree of Hydrologic regime in Jialing River basin is $50 \%$, which is moderate alteration.

(3) Precipitation is the dominant factor for runoff alteration, with its contribution to runoff alteration of $61 \%$, and the contribution of human activities and potential evapotranspiration of $55 \%$ and $16 \%$, respectively. The influence of climatic factors on runoff alteration gradually decreases with time.

(4) The obvious alteration in the hydrological situation in the basin will cause the ecological function of the Jialing River to be impaired, and the number of some drifting, rapid-flow habitatadapted fish and large economic fish will be significantly reduced.

\section{Study area and dataset}

\section{Study area}

Located between $29^{\circ} \sim 35^{\circ} \mathrm{N}$ and $102^{\circ} \sim 110^{\circ} \mathrm{E}$, the Jialing River is one of the main tributaries of the upper reaches of the Yangtze River. The mainstream is $1120 \mathrm{~km}$ long, passing through Shaanxi Province, Gansu Province, and Sichuan Province, and finally joins the Yangtze River in Chongqing City, with a basin area of about $16 \times 10^{4} \mathrm{~km}^{2}$, accounting for $15.9 \%$ of the Yangtze River basin area, and is a critical first-class tributary on the north bank of the Yangtze River, as well as the closest first-class tributary to the Three Gorges reservoir area in the upper reaches of the Yangtze River. Beibei hydrological station is located in Beibei District, Chongqing, a national primary hydrological station and is the controlling hydrological station for the outlet of the Jialing River basin, controlling $98 \%$ of the Jialing River basin ${ }^{34}$. 


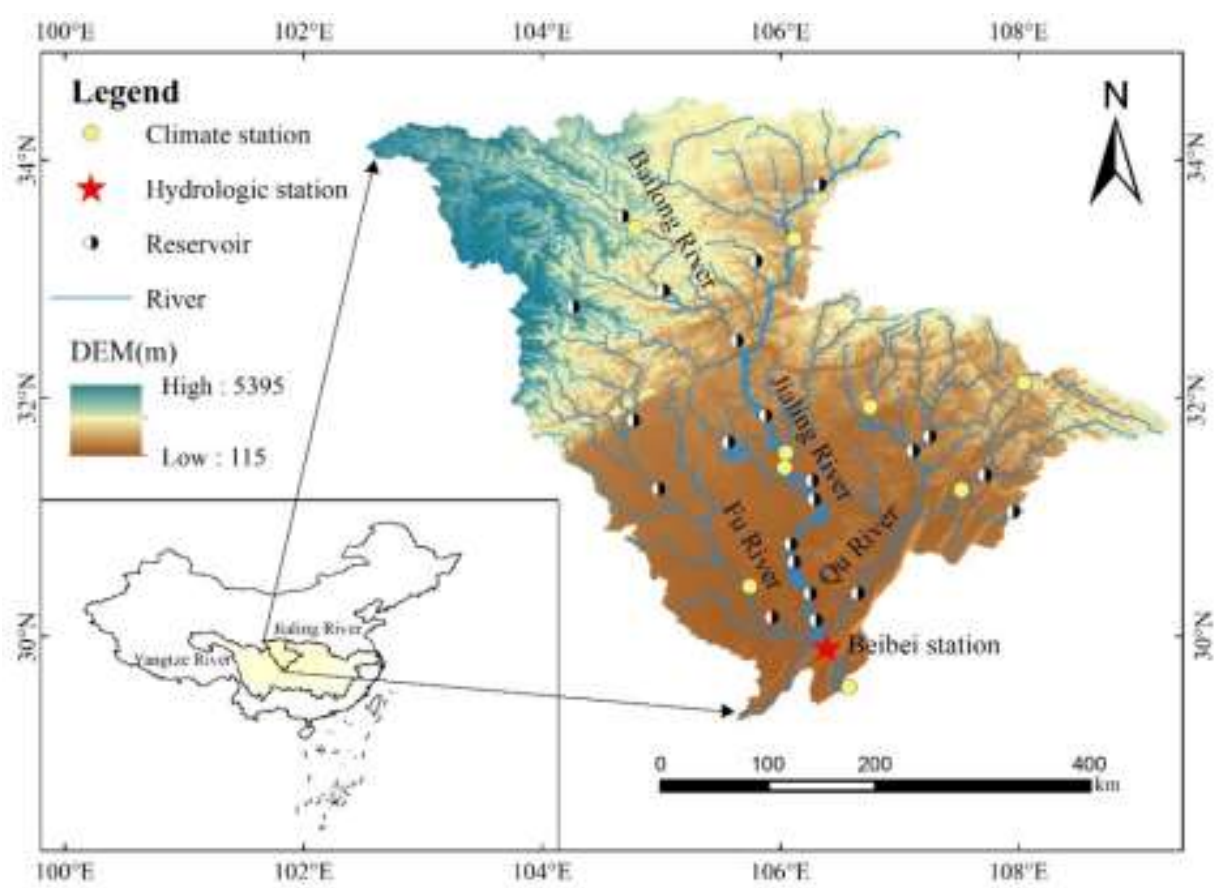

Fig. 9 Plan of Jialing River Basin

\section{Datasets}

The daily runoff data of the Jialing River-Beibei hydrological station from 1956 to 20 20 used in this study were obtained from the "Hydrological Yearbook of Yangtze River B asin." For the meteorological data, meteorological data from nine meteorological stations (F ig.9) in the Jialing River basin were used. The information was obtained from the China Meteorological Data Network (http://data.cma.cn/). The Normalized Difference Vegetation In dex (NDVI) used in this paper is based on the gridded data from 1998 to 2020 at $1 \mathrm{~km}$ resolution. The monthly NDVI is first obtained according to the maximum method. Then $t$ he monthly NDVI is averaged to obtain the annual NDVI. The land use data are the nati onal $1 \mathrm{~km}$ grid land use data for five periods of 1980, 1990, 2000, 2010, and 2018. The 1 and use data and NDVI for each period were sourced from the Resource and Environment Science and Data Center of the Chinese Academy of Sciences (https://www.resdc.cn/data.a spx), and the data production was generated by manual visual interpretation using Landsat TM/ETM remote sensing images as the primary data source for each period.

\section{Methods}

\section{Trend and mutation analysis}

In this paper, the Mann-Kendall non-parametric test ${ }^{35}$ and the cumulative distance level method ${ }^{36}$ mainly analyze the trend and mutation of the daily streamflow data observed at the Beibei hydrological station. Among them, the Mann-Kendall nonparametric test is a more widely used method to test the abruptness of runoff. Still, its detection results have a significant human interference factor and need to be combined with other abruptness detection methods and the actual situation to ensure its accuracy. Please refer to the corresponding references for the calculation process $^{35-36}$.

\section{IHA-RVA method}

To study rivers' complex hydrological alteration process, the hydrological alteration indicator 

used in this paper to analyze the alteration process. Based on the day-by-day water level data of the Beibei hydrological station, 32 IHA hydrological indicators were calculated (since there was no daily streamflow of zero at the Beibei hydrological station during the study period, the hydrological indicator of zero discharge was not considered in this study). According to different ecosystem effects, the 32 hands were divided into five groups (Table 7). The hydrological indicators of streamflow, time, frequency, duration, and alteration rate were integrated to evaluate. The hydrological state of the river was changed. To quantitatively analyze the interference degree of different hydrological indexes, the following quantitative index formula is adopted.

$$
\begin{gathered}
D_{i}=\left|\frac{N_{o i}-N_{e}}{N_{e}}\right| \times 100 \% \\
N_{e}=r \times N_{T}
\end{gathered}
$$

where: $D_{i}$ is the hydrological degree of alteration of the $i$ IHA indicator, $N_{0 i}$ and $N_{e}$ is the actual and desired number of years that fall within the RVA target threshold after the hydrological indicator alteration; $r$ is the proportion of the IHA falling within the RVA target threshold before the disturbance; $N_{T}$ is the total number of years after the hydrological indicator alteration.

To set an objective criterion for the degree of alteration, it is stipulated that $D_{i}$ values between 0 and $33 \%$ are considered unaltered or low alteration; between $33 \%$ and $67 \%$ are considered a moderate alteration, and $67 \%$ to $100 \%$ are considered a high alteration. The overall degree of hydrologic alteration $D_{o}$ can be calculated using the following method.

$$
D_{o}=\left(\frac{1}{n} \sum_{i=1}^{n} D_{i}^{2}\right)^{0.5}
$$

Where $n$ is the number of indicators, it is also specified that $D_{o}$ is between 0 and $33 \%, 33 \%$ and $67 \%$, and $67 \%$ and $100 \%$ are low media, and high alterations, respectively ${ }^{37}$.

\begin{tabular}{ccc}
\hline Group & IHA Parameters & Parameter index description \\
\hline 1 & Median month & Median monthly streamflow \\
2 & Annual pole size & $\begin{array}{c}\text { Tabnual average 1, 3, 7, 30, 90d minimum and maximum } \\
\text { streamflow (sand content), baseflow index }{ }^{(1)}\end{array}$ \\
3 & $\begin{array}{c}\text { Time of occurrence of annual } \\
\text { extreme value condition }\end{array}$ & $\begin{array}{c}\text { The date on which the maximum and minimum 1 day of the } \\
\text { year occurs (Roman day) }\end{array}$ \\
4 & $\begin{array}{c}\text { Frequency and duration of high } \\
\text { and low pulses }\end{array}$ & $\begin{array}{c}\text { Number of high and low pulses per year }{ }^{(3)} \text { and average of } \\
\text { pulse durations }\end{array}$ \\
5 & $\begin{array}{c}\text { Rate and frequency of alteration } \\
\text { in conditions }\end{array}$ & $\begin{array}{c}\text { Median annual values of increase (rate of increase) and } \\
\text { decrease (rate of decrease) and number of reversals }\end{array}$ \\
\hline
\end{tabular}

Note: (1) the ratio of the annual minimum continuous 7-day streamflow to the annual median; (2) Roman day indicates the number of days in the calendar year; (3) low pulse is defined as the median of the day lower than $25 \%$ of the frequency before the disturbance, and high pulse is defined as the median of the day higher than $75 \%$ of the frequency before the disturbance; (4) the number of reversals refers to the number of times the daily streamflow turns from increasing to decreasing or decreasing to increasing.

\section{Estimation of potential evapotranspiration}

In this study, the potential evapotranspiration is calculated using the FAO Penman-Monteith formula, which has been widely used by scholars:

$$
E T_{0}=\frac{0.408\left(R_{n}-G\right)+\gamma \frac{900}{T+273} \mu_{2}\left(e_{s}-e_{a}\right)}{\Delta+\gamma\left(1+0.34 \mu_{2}\right)}
$$

Where: $E T_{0}$ is the potential evapotranspiration $(\mathrm{mm} / \mathrm{d}) ; \Delta$ is the slope of the saturation water pressure curve $\left(\mathrm{Kpa} /{ }^{\circ} \mathrm{C}\right) ; R_{n}$ is the net surface radiation $\left(\mathrm{MJ} / \mathrm{m}^{2} \mathrm{~d}\right) ; G$ is the soil heat flux $\left(\mathrm{MJ} / \mathrm{m}^{2} \mathrm{~d}\right) ; \gamma$ is the dry and wettable constant $\left(\mathrm{Kpa} /{ }^{\circ} \mathrm{C}\right) ; T$ is the average daily air temperature 
$\left({ }^{\circ} \mathrm{C}\right) ; \mu_{2}$ is the wind speed at $2 \mathrm{~m}(\mathrm{~m} / \mathrm{s}) ; e_{s}$ is the saturation water pressure $(\mathrm{KPa}) ; e_{a}$ is the actual water pressure $(\mathrm{KPa})$. The specific calculation process is described in reference ${ }^{38}$.

\section{Quantitative evaluation of runoff alterations}

Runoff alterations in the basin should consider both climate and human activities ${ }^{39-40}$ and are calculated as follows.

$$
\begin{aligned}
\Delta \mathrm{R} & =\Delta R_{P}+\Delta R_{E}+\Delta R_{H} \\
\eta_{\mathrm{P}} & =\Delta \mathrm{R}_{P} / \Delta R \times 100 \% \\
\eta_{\mathrm{E}} & =\Delta R_{E} / \Delta R \times 100 \% \\
\eta_{H} & =\Delta R_{H} / \Delta R \times 100 \%
\end{aligned}
$$

Where: $\Delta \mathrm{R}$ is the difference of runoff depth alteration; $\Delta \mathrm{R}_{P}, \Delta \mathrm{R}_{E}, \Delta R_{H}$ is the amount of runoff depth alteration caused by climate alteration and human activities; $\eta_{P}, \eta_{E}, \eta_{H}$ is the contribution rate of climate alteration and human activities.

The elasticity coefficient method ${ }^{41-42}$ was chosen to calculate $\Delta R_{P}, \Delta R_{E}$ and $\Delta R_{H}$, based on the basin long time water balance equation $\left(\mathrm{R}=P-E_{\alpha}\right)$, the dryness index $\left(\phi=E_{0} / P\right)$ calculation and six formulas based on Budyko's assumptions (Table 8), as follows.

$$
\begin{gathered}
\Delta R_{P}=\varepsilon_{P} \frac{Q}{P} \Delta P \\
\Delta R_{E}=\varepsilon_{E} \frac{R}{E T_{O}} \Delta E \\
\varepsilon_{P}=1+\frac{\phi F^{\prime}(\phi)}{1-F(\phi)}, \text { and } \varepsilon_{E_{0}}=1-\varepsilon_{P}
\end{gathered}
$$

\begin{tabular}{|c|c|c|c|}
\hline No. & $F(\phi)$ & $F^{\prime}(\phi)$ & Source \\
\hline 1 & $F(\phi)=(1+\omega \phi) /(1+\omega \phi+1 / \phi), \omega=1$ & $F(\phi)^{\prime}=\left(\omega+2 \omega / \phi-1+1 / \phi^{2}\right) /(1+\omega \phi+1 / \phi)^{2}$ & $\begin{array}{c}\text { Zhang et al; } \\
2001\end{array}$ \\
\hline 2 & $1+\phi-\left(1+\phi^{a}\right)^{1 / a}, a=2.5$ & $1-\left(1+\phi^{a}\right)^{1 / a-1} \phi^{a-1}$ & Fu et al; 1981 \\
\hline 3 & $1-e^{-\phi}$ & $e^{-\phi}$ & Schreiber; 1904 \\
\hline 4 & {$\left[\phi \tanh (1 / \phi)\left(1-e^{-\phi}\right)\right]^{0.5}$} & $\begin{array}{l}0.5\left[\phi \tanh (1 / \phi)\left(1-e^{-\phi}\right)\right]^{-0.5} \times[\tanh (1 / \phi)- \\
\left.\operatorname{sech}^{2}(1 / \phi) / \phi\left(1-e^{-\phi}\right)+\phi \tanh (1 / \phi) e^{-\phi}\right]\end{array}$ & Budyko; 1948 \\
\hline 5 & $\left(1+\phi^{-2}\right)^{-0.5}$ & $1 /\left[\phi^{3}\left(1+(1 / \phi)^{2}\right)^{1.5}\right]$ & Pike; 1964 \\
\hline 6 & $\phi \tanh (1 / \phi)$ & $\tanh (1 / \phi)-4 /\left[\phi\left(e^{-1 / \phi}+e^{1 / \phi}\right)^{2}\right]$ & Ol'dekop; 1911 \\
\hline
\end{tabular}

where: $Q, E_{0}, P$ and are the multi-year average runoff, potential evapotranspiration, and precipitation, respectively; $\Delta E_{0}$ and $\Delta P$ are the alterations of potential evapotranspiration and precipitation before and after the impact, respectively; $\varepsilon_{P}$ and $\varepsilon_{E_{0}}$ are the elasticity indices of runoff to precipitation and potential evapotranspiration, respectively.

Tab.8 6 commonly used expressions based on Budyko hypothesis

\section{References}

399 1. Ge, J., Peng, W., Wei, H, W., Qu, X. \& Singh, S. Quantitative Assessment of Flow Regime Alterat ion Using a Revised Range of Variability Methods. Water 10(5), 597 (2018).

401 2. Latrubesse, E.M., Arima, E.Y., Dunne, T., Park, E., Baker, V.R., D Horta, F.M., Wight, C., Wittman 
n, F., Zuanon, J., Baker, P.A., Ribas, C.C., Norgaard, R.B., Filizola, N., Ansar, A., Flyvbjerg, B. \& Stevaux, J.C. Damming the rivers of the Amazon basin. Nature 546(7658), 363-369 (2017).

3. Meade, R. H. \& Moody, J. A. Causes for the decline of suspended-sediment discharge in the Missis sippi River system, 1940-2007. Hydrol. Process 24(1), 35-49 (2010).

4. Fathi, M. M., Awadallah, A. G., Abdelbaki, A. M. \& Haggag, M. A new Budyko framework extens ion using time series SARIMAX model. Journal of Hydrology 570, 827-838 (2019).

5. Wang, H., Liu, J. \& Guo, W. The variation and attribution analysis of the runoff and sediment in $t$ he lower reach of the Yellow River during the past 60 years. Water Supply 21(6), (2021).

6. Guo, S., Guo, J., Hou, Y., Xiong, L. \& Hong, X. Prediction of future runoff change based on Bud yko hypothesis in Yangtze River basin. Advances in Water Science 26(02), 151-160 (2015).

7. Zhang, X., Dong, Z., Gupta, H., Wu, G. \& Li, D. Impact of the Three Gorges Dam on the Hydrol ogy and Ecology of the Yangtze River. Water 8(12), (2016).

8. Zhang, J., Zhang, M., Song, Y. \& Lai, Y. Hydrological simulation of the Jialing River Basin using the MIKE SHE model in changing climate. Journal of Water and Climate Change 12(6), (2021).

9. Richter B. D., Baumgartner, J. V., Powell, J. \& Braun, P. D. A method for assessing hydrologic alt eration within ecosystems. Conservation Biology 10(4), 1163-1174 (1996).

10. Richter, B. D., Baumgartner, J. V., Wigington, B. \& Braun, D. How much water does a river need?. Freshwater Biology 37(1), 231-249 (1997).

11. Richter, B. D., Baumgartner, J. V., Braun D. P. \& Powell, J. A spatial assessment of hydrologic alte ration within a river network. Regulated River Research and Management 14(4), 329-340 (1998).

12. Guo, W., Xu, G., Shao, J., Bing, J. \& Chen, X. Research on the Middle and Lower Reaches of the Yangtze River and Lake's Hydrological Alterations Based on RVA. IOP Conference Series: Earth and Environmental Science 153(6), (2018).

13. Guo, W., Li, Y., Wang, H. \& Zha, H. Assessment of Eco-hydrological Regime of Lower Reaches of Three Gorges Reservoir Based on IHA-RVA. Resources and Environment in the Yangtze Basin 27(09), 2014-2021 (2018).

14. Zuo, Q. \& Liang, S. Effects of dams on river flow regime based on IHA/RVA. Proceedings of the International Association of Hydrological Sciences 368(368), (2015).

15. Mwedzi, T., Katiyo, L., Mugabe, F. T., Bere, T. \& Kuoika, O. L. A spatial assessment of stream-flo $\mathrm{w}$ characteristics and hydrologic alterations, post dam construction in the Manyame catchment, Zimb abwe. Water Sa 42(2), (2016).

16. Liu, J., Chen, J., Xu, J., Lin, Y. \& Zhou, M. Attribution of Runoff Variation in the Headwaters of the Yangtze River Based on the Budyko Hypothesis. International Journal of Environmental Researc $h$ and Public Health 16(14), (2019).

17. Yan, D. Using Budyko-Type Equations for Separating the Impacts of Climate and Vegetation Change on Runoff in the Source Area of the Yellow River. Water 12(12), (2020).

18. Gunkel, A. \& Lange, J. Water scarcity, data scarcity and the Budyko curve-An application in the Lower Jordan River Basin. Journal of Hydrology: Regional Studies 12(C), 136-149 (2017).

19. Fathi, M. M., Awadallah, A. G., Abdelbaki, A. M. \& Haggag M. A new Budyko framework extensi on using time series SARIMAX model. Journal of Hydrology 570, 827-838 (2019).

20. Li, Y., Fan, J. \& Liao, Y. Variation Characteristics of Streamflow and Sediment in the Jialing River Basin in the Past 60 Years. Mountain Research 38(03), 339-348 (2020).

21. Liu, Y., Li, F. \& Xu, X. Impacts of hydropower development on hydrological regime in mainstream of midlower Jialing River. Yangtze River 45(05), 10-15 (2014). 
22. Zhou, Y., Li, J., Lu, J., Yao, S., Yan, X., Jin, Z., Liu, L. \& Lu, X. Distinguishing the multiple con trols on the decreased sediment flux in the Jialing River basin of the Yangtze River, Southwestern China. Catena 193(C), (2020).

23. Yan, M., Fang, G. H., Dai, L. H., Tan, Q. F. \& Huang, X. F. Optimizing reservoir operation considering downstream ecological demands of water quantity and fluctuation based on IHA parameters. Journal of Hydrology (4), 126647 (2021).

24. Wei, R., Liu, J., Zhang, T., Zeng, Q. \& Dong, X. Attribution Analysis of Runoff Variation in the Upper-Middle Reaches of Yalong River. Resources and Environment in the Yangtze Basin 29(07), 16 43-1652 (2020).

25. Song, M. \& Chen, J. Analysis on variation trend of rainfall-runoff relationship in Xihanshui Basin o f Jialing River. Yangtze River 113(3), 030602-030602 (2014).

26. Guo, W., Jin, Y., Li, Y., Shi, M. \& Wang, H. Quantitative Assessment of the Impact of Climate Ch ange and Human Activities on the Hydrological Regime in the Middle and Lower Reaches of the $\mathrm{Y}$ angtze River During the Past 60 Year. Resources and Environment in the Yangtze Basin 30(10), 246 4-2470 (2021).

27. Liao, C., Han, F. \& Feng, M. Construction achievement and experience of soil and water conservati onr. Yangtze River 41(13), 16-20 (2010).

28. Li, H. \& Zhang, Y. Analysis of characteristics of inflow and outflow runoff and sediment in Three Gorges Reservoir and its influential factors. Yangtze River 46(05), 13-18 (2015).

29. Zhang, H., Kang, M., Shen, L., Wu, J., Li, J., Du, H., Wang, C., Yang, H., Zhou, Q., Liu, Z., Harry, G. \& Wei, Q. Rapid change in Yangtze fisheries and its implications for global freshwater ecosystem management. Fish and Fisheries 21(3), (2021).

30. Liu, Y., Feng, X., Pu, D., Gu, H., Tian, J., Zhao, Z., Huang, J., Zhu, J. \& Wang, Z. Characteristics and resource status of main commercial fish in the middle reaches of Jialing River. Chinese Journ al of Applied and Environmental Biology 27(04), 837-847 (2021).

31. Zeng, J. Taxonomic Diversity of Fishes in the Main Section of the Jialing River. Journal of China West Normal University 33(03), 246-250 (2010).

32. Xu, W., Qiao, H. \& Gong, Y. Chang of fish resources in upper Yangtze River and its protection. $Y$ angtze River 43(01), 67-71 (2012).

33. Sun, Z., Zhang, M. \& Chen, Y. Protection of the rare and endemic fish in the conservation area lo cated in the upstream of the Yangtze River. Freshwater Fisheries 44(06), 3-8 (2014).

34. Wang, Y., Wang, S., Wu, M. \& Wang, S. Impacts of the Land Use and Climate Changes on the Hydrological Charateristics of Jialing River Basin. Research of Soil and Water Conservation 26(01), 135-142 (2019).

35. Zhuo, Z., Qian, Z., Jiang, H, Wang, H. \& Guo, W. Evaluation of Hydrological Regime in Xiangjiang Basin on IHA-RVA Method. China Rural Water and Hydropower (08), 188-192 (2020).

36. Chen, L., Wang, Y., Touati, B., Guan, H., Leng, G. Liu, W., Lv, S., Huang, S. \& Pan, Z. Temporal characteristics detection and attribution analysis of hydrological time-series variation in the seagoing river of southern China under environmental change. Acta Geophysica 66(5), (2018).

37. Zhang, R., Liu, J., Mao, G. \& Wang, L. Flow regime alterations of upper Heihe River based on improved RVA. Arid Zone Research 38(01), 29-38 (2021).

38. Sun, Y. \& Wang, X. Changes in Runoff and Driving Force Analysis in the Key Section of the Yellow River Diversion Project. Journal of Hydroecology 41(06), 19-26 (2020).

39. Zhang, L., Dawes, W. R. \& Walker, G. R. Response of mean annual evapotranspiration to vegetation changes at catchment scale. Water Resources Research 37(3), 2001. 
40. Fu, B. Calculation of soil evaporation. Acta Meteorologica Sinica (02), 226-236 (1981).

41. Liu, J., Zhang, Q., Singh, V. P. \& Shi, P. Contribution of multiple climatic variables and human act ivities to streamflow changes across China. Journal of Hydrology 545, 145-162 (2017).

42. Yang, D., Zhang, S. \& Xu, X. Attribution analysis for runoff decline in Yellow River Basin during past fifty years based on Budyko hypothesis. Scientia Sinica 45(10), 1024-1034 (2015).

\section{Acknowledgment}

496 We much appreciate the contributions of the experts who participated in this review. This stud $497 \mathrm{y}$ was supported by the National Nature Science Foundation of China (Grant No. 51779094);

498 Water Conservancy Science and Technology Project of Guizhou Province (KT202008); The Wis 499 dom Introduction Project of Henan Province (GH2019032)

\section{Author Contributions}

501 Wenxian Guo and Xuyang Jiao: Data curation, Writing - original draft, Methodology, Funding

502 acquisition. Yongwei Zhu and Haotong Zhou: Conceptualization, Supervi-sion, Funding acquisiti

503 on. Hongxiang Wang: Conceptualization, Supervi-sion, Project administration.

\section{Additional Information}

505 Competing Interests: The authors declare that they have no competing interests.

506 Publisher's note: Springer Nature remains neutral with regard to jurisdictional claims in publish 507 ed maps and institutional affiliations. 